\title{
Estudo de distribuição e morfologia dos melanócitos em pele com e sem exposição solar
}

Primeira submissão em 15/07/09 Última submissão em 08/12/09 Aceito para publicação em 07/02/10 Publicado em 20/02/10

\author{
Melanocytes distribution and morphology analysis in skin with and without sun exposure
}

Daniela Mayumi Takano'; Maria do Carmo Abreu e Lima²

\begin{abstract}
unitermos
Melanócitos

Densidade

Morfologia

\section{resumo}

Introdução e objetivos: Acredita-se que a exposição solar possa alterar número, distribuição e morfologia dos melanócitos na pele humana, muitas vezes dificultando a interpretação de biópsias de pele, principalmente para o diagnóstico de lesões melanocíticas iniciais e para a avaliação precisa de margens de ressecção. $O$ objetivo deste trabalho foi avaliar os melanócitos da pele humana em área exposta e não exposta ao sol. Métodos: Realizada análise histológica de 60 fragmentos de biópsias de pele obtidas do antebraço (área fotoexposta) e região glútea (área coberta) de cadáveres do Serviço de Verificação de Óbitos de Recife-PE. A estatística foi realizada com o SPSS Windows versão 12.0. Resultados: Observou-se um número bastante variável de melanócitos nos fragmentos de pele, com maior concentração destes na região do antebraço (área de maior fotoexposição) $(p<0,001)$. Notou-se também uma distribuição irregular dos melanócitos ao longo da camada basal da epiderme, por vezes com células dispostas lado a lado. Essa confluência foi identificada com maior frequência na área fotoexposta $(p=0,035)$, não se observando mais que quatro melanócitos adjacentes. A atipia citológica foi encontrada em $40 \%$ das amostras de pele da área fotoexposta, estando ausente na área fotoprotegida. Não se verificou em nenhuma das amostras a formação de ninhos ou a presença de disseminação pagetoide. Conclusão: Há grande variabilidade de densidade, morfologia e distribuição dos melanócitos na pele humana, principalmente em área fotoexposta. Comentário: A presença de atipia citológica e confluência celular não devem ser usadas como critério isolado para a definição de uma lesão neoplásica.
\end{abstract}

\section{abstract}

Introduction and objectives: It is believed that sun exposure can change the number, distribution and morphology of melanocytes in human skin, which often hinders the interpretation of skin biopsies, mainly as to diagnosis of initial melanocytic lesions and accurate assessment of resection margins. Our objective was to evaluate melanocytes in sun-exposed and non-exposed skin. Methods: It was conducted the histological analysis of 60 skin biopsy samples resected from cadaver forearm (sun-exposed skin) and cadaver buttock (non-exposed skin) from the Death Verification Service (Serviço de Verificação de Óbitos) of Recife, state of Pernambuco. The statistical analysis was performed with SPSS Windows version 12.0. Results: There was considerable variability in melanocyte density, with a higher concentration of these cells in sun-exposed areas ( $p$ $<0.001$ ). There was also an irregular distribution of melanocytes along the epidermal basal layer, occasionally with cells arranged side by side. This confluence was identified with a higher frequency in sun-exposed areas $(\mathrm{p}=0.035)$ and did not exceed more than 4 adjacent melanocytes. Cytological atypia was found in $40 \%$ of sun-exposed skin samples and was absent in non-exposed areas. Neither nests of melanocytes nor pagetoid spread was observed. Conclusion: There is a great variability in the density, distribution and morphology of melanocytes in human skin, mostly in sun-exposed areas. Comment: The presence of cytological atypia and cell confluence should not be used as isolated criteria for the definition of a neoplastic lesion. key words

Melanocytes

Density

Morphology

1. Mestre em Patologia pela Universidade Federal de Pernambuco (UFPE).

2. Doutora em Medicina pela UFPE; programa de pós-graduação em Patologia pela UFPE. 


\section{Introdução}

Os primeiros estudos sobre número, distribuição e características dos melanócitos na pele humana foram realizados por meio da reação de dopamina em preparados de epiderme após clivagem em solução salina. Observou-se grande variabilidade na distribuição dessas células entre os indivíduos e conforme a região anatômica, com presença ocasional de dismorfismos citológicos, mais evidentes nas áreas de maior fotoexposição ${ }^{(5,7,9,12,13)}$. Tais estudos foram muito importantes para o entendimento inicial da distribuição dos melanócitos na pele humana e sua variação com a exposição solar. Entretanto, a técnica histoquímica aplicada é complexa e não fornece dados comparativos para a interpretação de preparações histológicas utilizadas na prática médica atual.

A proliferação anormal dos melanócitos pode dar origem a uma grande variabilidade de neoplasias benignas e malignas, com características clínicas e anatomopatológicas distintas. O melanoma, tumor maligno originado nos melanócitos, é a neoplasia cutânea de maior importância clínica, apesar de sua menor prevalência, pois muitas vezes pode apresentar curso clínico fatal, com tendência a disseminação linfática e hematogênica ${ }^{(8)}$. A prevenção primária e a detecção precoce são as formas mais promissoras para diminuir a mortalidade relacionada ao melanoma. Dessa forma, diversos esforços têm sido empregados para melhor compreender as etapas da tumorigênese dessa neoplasia, visando fornecer maior número de critérios para o diagnóstico e auxiliar na identificação dos indivíduos de maior suscetibilidade para o desenvolvimento dessa doença.

Fatores constitucionais individuais, região anatômica e alterações ambientais, em especial a fotoexposição, parecem influenciar número, morfologia e forma de distribuição dos melanócitos. O reconhecimento dessas variações é de fundamental importância para a interpretação de biópsias de pele, principalmente para o diagnóstico de lesões iniciais e para a avaliação precisa das margens de ressecção.

Este estudo visou obter informações sobre densidade, distribuição e morfologia dos melanócitos na pele humana sem lesão macroscópica em preparações histológicas usadas na prática médica de rotina e verificar a influência da exposição solar nas características dessas células.

\section{Métodos}

Foram obtidas amostras de pele de cadáveres do Serviço de Verificação de Óbitos (SVO) de Recife-PE por intermédio de biópsia realizada por punch de $5 \mathrm{~mm}$, coletadas de áreas sem lesão macroscópica aparente, provenientes do membro superior, antebraço, face lateral (área fotoexposta) e da região glútea (área fotoprotegida duplamente coberta). Os pacientes foram classificados por idade, sexo e tipo reativo de pele (I-VI, conforme os critérios de Fitzpatrick).

O projeto de pesquisa foi encaminhado ao Comitê de Ética da Universidade Federal de Pernambuco (UFPE) com aprovação sob a resolução no 196/96 em 23/10/2007.

O material foi submetido a processamento histológico e corado pela técnica de hematoxilina e eosina. A junção dermoepidérmica foi avaliada em 10 campos de grande aumento (400x), e o resultado foi expresso em número médio de melanócitos por campo de grande aumento (CGA). As lâminas foram nomeadas por códigos, impossibilitando a identificação da amostra. O reconhecimento dos melanócitos foi feito por meio de suas características morfológicas. Foram contados apenas os melanócitos presentes em um mesmo plano e com núcleos completamente visíveis.

A confluência dos melanócitos foi avaliada e classificada conforme o número de células dispostas lado a lado. Dessa forma, consideraram-se: ausência de confluência, confluência leve (dois a três melanócitos), moderada (quatro a cinco melanócitos) e acentuada (mais do que cinco melanócitos). Procurou-se também pela formação de ninhos (definida como quatro melanócitos em íntimo contato) e presença de disseminação pagetoide (ascensão de melanócitos para as demais camadas do epitélio).

A atipia citológica foi definida como ausente ou presente, observando-se as seguintes alterações da morfologia: aumento do volume nuclear, nucléolo evidente, pleomorfismo, hipercromasia, binucleação e multinucleação.

Foi realizado um estudo imuno-histoquímico complementar para o antígeno Melan-A (Clone A103, DAKO) em 10 amostras aleatórias de pele da área fotoexposta (membro superior) e em 10 amostras da área fotoprotegida (região glútea) para fins comparativos. Realizou-se, inicialmente, a reação com o anticorpo monoclonal anti-MelanA/MART-1 revelada pelo cromógeno diaminobenzidina (DAB) com contracoloração pela hematoxilina de Harris. Em um segundo momento, em casos selecionados, foi utilizada a contracoloração com Giemsa, conforme metodologia proposta por Sálvio \& Marques em 2006 ${ }^{(11)}$, para facilitar a distinção entre a positividade da cor marrom acastanhada fornecida pelo cromógeno DAB do pigmento marrom de melanina presente nos ceratinócitos. Essa análise complementar foi realizada em caráter ilustrativo, com o objetivo de verificar, entre as técnicas disponíveis, qual seria a melhor 
para evidenciar os melanócitos na pele humana sem lesão macroscópica. Todavia, a metodologia escolhida para a contagem de melanócitos neste estudo foi a avaliação de preparações histológicas coradas pela hematoxilina e eosina, dada sua maior aplicabilidade na rotina do diagnóstico histopatológico e seu baixo custo.

O nível de significância assumido foi de $5 \%$. Os cálculos estatísticos foram realizados no software SPSS for Windows versão 12.0 (Statistical Package for the Social Science).

\section{Resultados}

Foram obtidas 60 amostras de pele de 30 cadáveres do SVO. Dessas, 18 eram do sexo masculino e 12, do sexo feminino. Apresentavam ampla distribuição de faixa etária, com idade média de 57,57 anos (desvio padrão [DP] = 23,97 anos). Em relação ao tipo reativo de pele, a maior parte da amostra era representada pelos subtipos III, IV e V (Tabela 1).

\section{Características da amostra e número, confluência e atipia de melanócitos conforme a}

\section{Tabela 1 fotoexposição}

\begin{tabular}{|c|c|c|c|c|c|c|c|c|c|}
\hline & \multirow[b]{2}{*}{ Idade } & \multirow[b]{2}{*}{ Sexo } & \multirow[b]{2}{*}{$\begin{array}{c}\text { Tipo de } \\
\text { pele }\end{array}$} & \multicolumn{3}{|c|}{ Área fotoexposta } & \multicolumn{3}{|c|}{ Área fotoprotegida } \\
\hline & & & & $\begin{array}{c}\text { Melanócitos/ } \\
\text { CGA }\end{array}$ & Confluência & $\begin{array}{c}\text { Atipia } \\
\text { citológica }\end{array}$ & $\begin{array}{c}\text { Melanócitos/ } \\
\text { CGA }\end{array}$ & Confluência & $\begin{array}{c}\text { Atipia } \\
\text { citológica }\end{array}$ \\
\hline 1 & 44 & Masc. & V & 7,4 & $\mathrm{~N}$ & N & 3,9 & L & N \\
\hline 2 & 38 & Masc. & IV & 4,9 & L & $\mathrm{N}$ & 5,4 & $\mathrm{~N}$ & N \\
\hline 3 & 9 & Masc. & III & 10,8 & M & $\mathrm{N}$ & 6,1 & $\mathrm{~N}$ & $\mathrm{~N}$ \\
\hline 4 & 77 & Masc. & V & 4 & $\mathrm{~N}$ & N & 2,4 & $\mathrm{~N}$ & $\mathrm{~N}$ \\
\hline 5 & 66 & Fem. & VI & 3,7 & N & N & 3,4 & $\mathrm{~N}$ & $\mathrm{~N}$ \\
\hline 6 & 91 & Fem. & VI & 14,9 & $L$ & N & 2,1 & $\mathrm{~L}$ & $\mathrm{~N}$ \\
\hline 7 & 74 & Masc. & IV & 7 & $\mathrm{~L}$ & N & 3,6 & $\mathrm{~N}$ & $\mathrm{~N}$ \\
\hline 8 & 67 & Masc. & V & 5 & $L$ & N & 5,1 & $\mathrm{~N}$ & $\mathrm{~N}$ \\
\hline 9 & 70 & Masc. & VI & 5,9 & L & $\mathrm{N}$ & 3,6 & $\mathrm{~L}$ & $\mathrm{~N}$ \\
\hline 10 & 43 & Masc. & IV & 11,6 & $L$ & $S$ & 5,3 & $\mathrm{~N}$ & $\mathrm{~N}$ \\
\hline 11 & 1 & Masc. & VI & 9,6 & $L$ & N & 7,1 & $\mathrm{~N}$ & $\mathrm{~N}$ \\
\hline 12 & 73 & Masc. & III & 9,1 & $L$ & $S$ & 6,8 & $\mathrm{~N}$ & $\mathrm{~N}$ \\
\hline 13 & 54 & Fem. & IV & 6,7 & $\mathrm{~N}$ & $S$ & 4,9 & $\mathrm{~L}$ & $\mathrm{~N}$ \\
\hline 14 & 25 & Masc. & III & 11,5 & $L$ & $S$ & 7,4 & $\mathrm{~N}$ & $\mathrm{~N}$ \\
\hline 15 & 88 & Masc. & IV & 8,2 & $\mathrm{~L}$ & $S$ & 4,5 & $\mathrm{~N}$ & $\mathrm{~N}$ \\
\hline 16 & 49 & Fem. & IV & 6,4 & $\mathrm{~N}$ & $S$ & 5,7 & $\mathrm{~N}$ & $\mathrm{~N}$ \\
\hline 17 & 67 & Masc. & III & 7,8 & $\mathrm{~L}$ & $\mathrm{~N}$ & 5,3 & $\mathrm{~L}$ & $\mathrm{~N}$ \\
\hline 18 & 67 & Fem. & III & 4,3 & $\mathrm{~N}$ & $S$ & 4,9 & $L$ & $\mathrm{~N}$ \\
\hline 19 & 79 & Masc. & III & 11 & $\mathrm{~L}$ & $S$ & 6 & $\mathrm{~L}$ & $\mathrm{~N}$ \\
\hline 20 & 63 & Fem. & III & 4,7 & $\mathrm{~N}$ & $S$ & 5,1 & $\mathrm{~N}$ & $\mathrm{~N}$ \\
\hline 21 & 44 & Fem. & IV & 12,2 & $\mathrm{~L}$ & $\mathrm{~N}$ & 6,9 & $L$ & $\mathrm{~N}$ \\
\hline 22 & 61 & Fem. & V & 4,2 & $\mathrm{~N}$ & $\mathrm{~N}$ & 3,8 & $\mathrm{~N}$ & $\mathrm{~N}$ \\
\hline 23 & 51 & Masc. & V & 10,3 & $L$ & $S$ & 5,9 & $\mathrm{~L}$ & $\mathrm{~N}$ \\
\hline 24 & 91 & Fem. & II & 5,2 & $\mathrm{~L}$ & $\mathrm{~N}$ & 4,6 & $\mathrm{~N}$ & $\mathrm{~N}$ \\
\hline 25 & 82 & Masc. & V & 9,2 & $L$ & $\mathrm{~N}$ & 4,3 & $\mathrm{~N}$ & $\mathrm{~N}$ \\
\hline 26 & 30 & Masc. & VI & 5,4 & $\mathrm{~N}$ & $\mathrm{~N}$ & 4 & $\mathrm{~N}$ & $\mathrm{~N}$ \\
\hline 27 & 22 & Masc. & IV & 14,9 & $L$ & $S$ & 7,2 & $\mathrm{~N}$ & $\mathrm{~N}$ \\
\hline 28 & 82 & Fem. & II & 2,4 & $\mathrm{~N}$ & $\mathrm{~N}$ & 0,5 & $\mathrm{~N}$ & $\mathrm{~N}$ \\
\hline 29 & 78 & Fem. & II & 8,4 & $\mathrm{~L}$ & $\mathrm{~N}$ & 6 & $L$ & $\mathrm{~N}$ \\
\hline 30 & 41 & Fem. & V & 5,4 & $\mathrm{~N}$ & $S$ & 3,8 & $\mathrm{~N}$ & $\mathrm{~N}$ \\
\hline
\end{tabular}

$\mathrm{N}$ : ausente; S: presente; L: leve; M: moderada; A: acentuada. 
O número médio de melanócitos nos fragmentos de pele do antebraço (área fotoexposta) foi de 7,74 melanócitos/ $\mathrm{CGA}(\mathrm{DP}=3,31)$ e, nos da região glútea, área duplamente coberta (fotoprotegida), foi de 4,85 melanócitos/CGA (DP = $1,60)$. Essa diferença foi estatisticamente significativa (teste $\mathrm{t}$ de student pareado $-p<0,001$ ) (Figura 1).

Em relação à faixa etária, apenas na área fotoprotegida, notou-se menor média de melanócitos quanto maior a idade (coeficiente de correlação de Pearson, $r=-0,544$, $p=0,002$ ) (Figura 2).

Não se observou diferença estatisticamente significativa no número médio de melanócitos entre homens e mulheres, tanto para a área fotoexposta quanto para a fotoprotegida (teste $t, p=0,108$ e 0,129, respectivamente). Para fins de cálculos estatísticos, agruparam-se os subtipos reativos de pele em três diferentes categorias, I-II, III-IV e V-VI. Não se verificou diferença significativa entre o número médio de melanócitos e os diferentes tipos reativos de pele na área

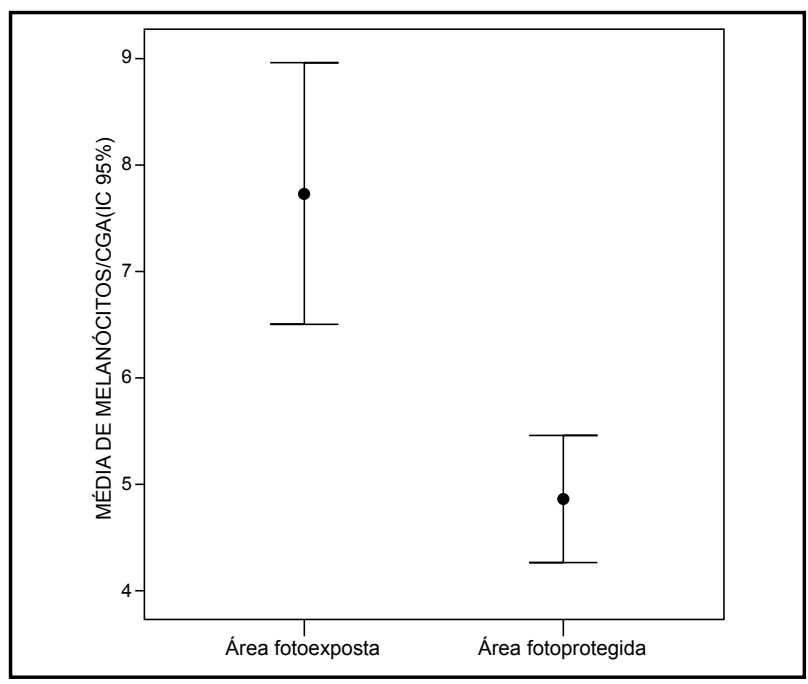

Figura 1 - IC de 95\% para as médias de melanócitos segundo a fotoexposição (média da área fotoexposta = 7,74 e DP =3,31; média da área fotoprotegida $=4,85$ e DP = 1,6) IC: intervalo de confiança; DP: desvio padrão.

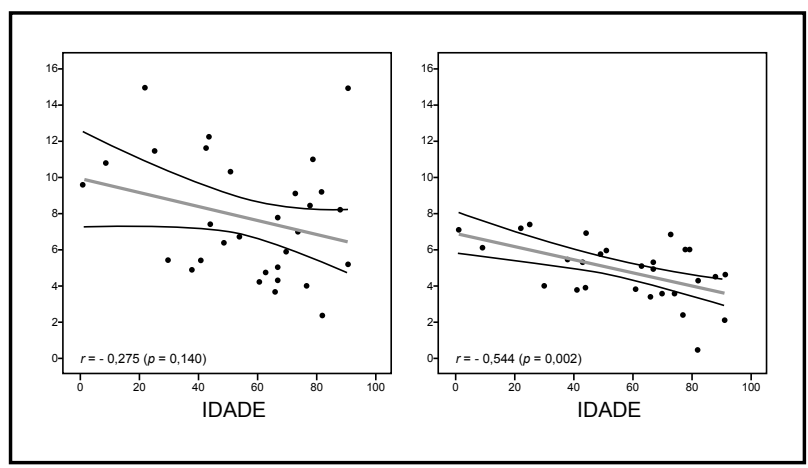

Figura 2 - Diagrama de dispersão da média de melanócitos segundo a idade nas áreas fotoexposta e fotoprotegida r: correlação de Pearson. fotoexposta. Já na área fotoprotegida, o número médio de melanócitos dos grupos III-IV e V-VI mostrou-se diferente (Anova, $p=0,029$ ).

A distribuição dos melanócitos ao longo da camada basal da epiderme mostrou-se bastante irregular, tanto na área fotoexposta como na fotoprotegida, notando-se setores de maior e menor celularidade no mesmo fragmento de pele. A disposição lado a lado dessas células (confluência) foi encontrada tanto na área fotoexposta como na fotoprotegida, porém foi identificada em uma proporção maior de casos na área fotoexposta (63,3\%) (teste de McNemar, $p=$ $0,035)$. Deve-se destacar que não se observou em nenhum dos fragmentos mais que quatro melanócitos dipostos de forma contínua (Figuras 3 e 4).

A atipia citológica foi encontrada apenas na pele da área fotoexposta e identificada em 12 (40\%) dos casos (Figuras 5 e 6).

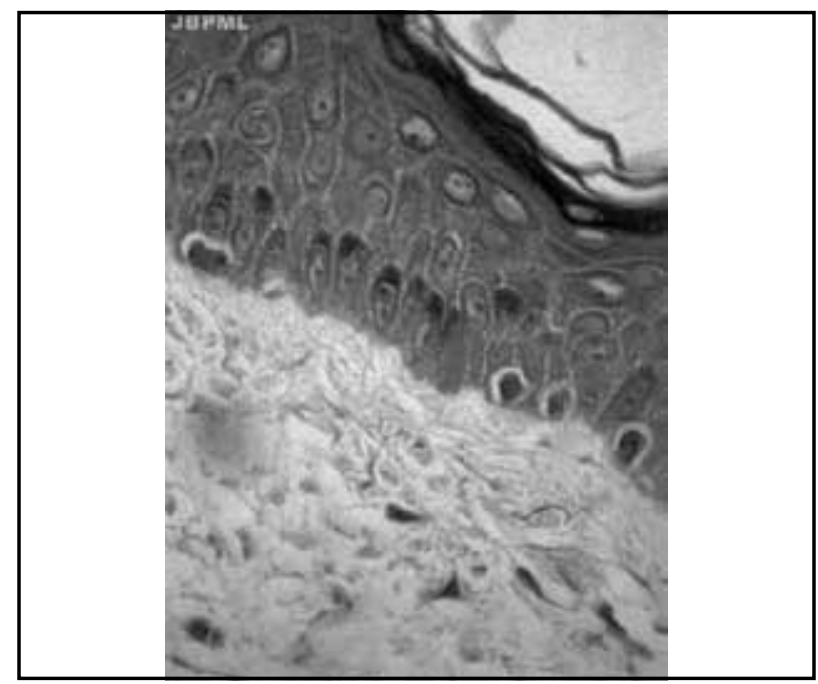

Figura 3 - Distribuição irregular dos melanócitos ao longo da camada basal. Hematoxilina e eosina (400x)

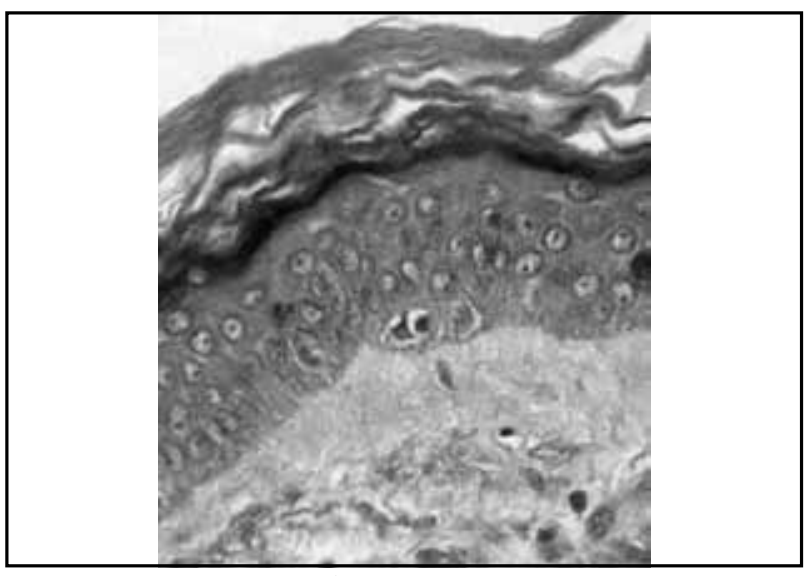

Figura 4 - Confluência de melanócitos. Hematoxilina e eosina (400x) 


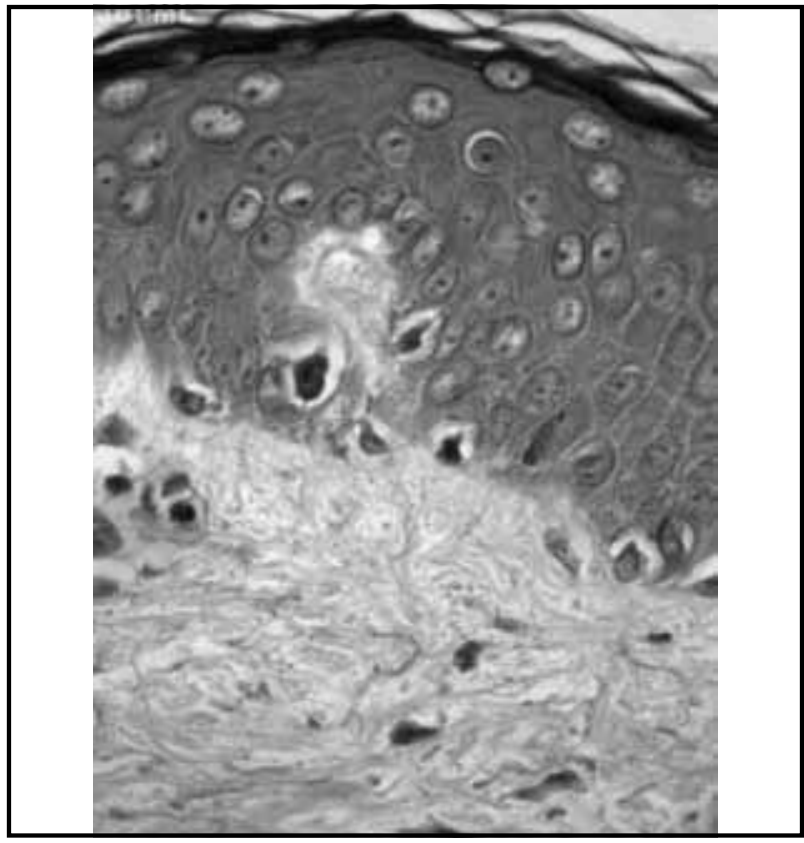

Figura 5 - Pleomorfismo citológico. Hematoxilina e eosina (400x)

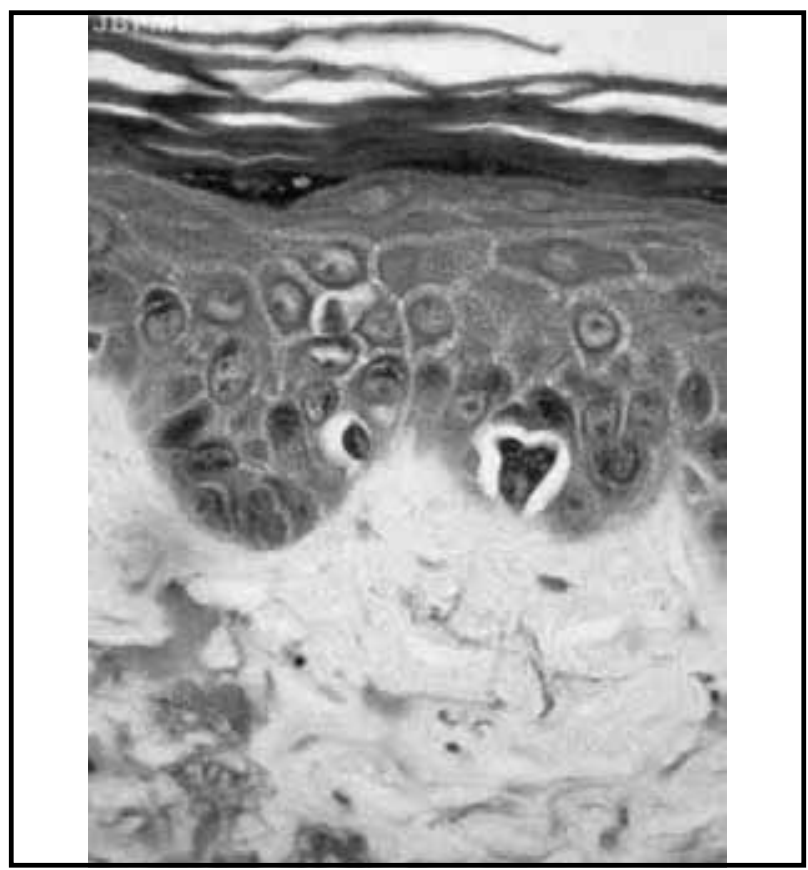

Figura 6 - Atipia citológica. Hematoxilina e eosina (1.000x)
A idade média do grupo de pacientes que exibiram atipia citológica foi de 54,58 anos, com valores variando de 22 a 88 anos. No grupo de pacientes sem atipia citológica, a idade variou de 1 a 91 anos, com média de 59,56 anos. Não houve diferença significativa entre a média de idades dos grupos segundo a presença de atipia citológica (teste $t$ student, $p=0,587$ ) (Tabela 2).

\section{Discussão}

Observamos uma diferença significativa do número médio de melanócitos entre os fragmentos de pele obtidos do membro superior e da região glútea de um mesmo indivíduo. Tal achado está possivelmente relacionado com a presença da exposição solar, uma vez que a região glútea é duplamente coberta e a do antebraço está mais frequentemente exposta ao sol. Resultado semelhante foi encontrado por Fallowfield et al. ${ }^{(4)}$. Deve-se ressaltar, entretanto, que a localização anatômica é fator importante para a determinação da densidade dos melanócitos na pele humana, com maiores densidades encontradas na região de cabeça/pescoço e genitais masculinos, seguidas do dorso, membro superior e membro inferior ${ }^{(7,12,13,15)}$. O encontro de grande número de melanócitos na região dos genitais, área também duplamente coberta, reforça a ideia de que fatores outros, além da exposição solar, influenciam a determinação da densidade dessa célula. Whiteman et al. ${ }^{(15)}$ sugerem que fatores embriológicos estejam envolvidos nessa distribuição anatômica, de forma semelhante ao que ocorre com os folículos pilosos.

A influência da exposição solar como um determinante da variação da densidade de melanócitos foi previamente avaliada de diversas formas. Quevedo et al.(9) e Gilchrest et al. ${ }^{(5)}$ relataram maior número dessas células na área de maior fotoexposição, porém utilizaram para a avaliação método histoquímico que marca apenas as células sensíveis à dopamina (reação de dopamina). Dessa forma, não se pode

\section{Tabela 2 Média de idade conforme a presença de atipia citológica dos melanócitos}

\begin{tabular}{lcccccc}
\hline Atipia & $n$ & Média & Mediana & Desvio padrão & Mínimo & Máximo \\
Não & 18 & 59,56 & 67 & 26,47 & 1 & 91 \\
Sim & 12 & 54,58 & 52,50 & 20,40 & 22 & 88 \\
Total & 30 & 57,57 & 64,50 & 23,97 & 1 & 91
\end{tabular}

$p=0,587$. 
excluir a possibilidade de ter ocorrido apenas a ativação da tirosinase pela luz solar em melanócitos preexistentes primeiramente dopanegativos, resultando em maior número de células positivas. Whiteman et al. ${ }^{(15)} \mathrm{e} \mathrm{Hendi} \mathrm{et} \mathrm{al.}{ }^{(6)}$ avaliaram a exposição solar por meio de questionários. Em nenhum dos trabalhos, observou-se a associação de maior número de melanócitos com a presença da história de exposição solar. No primeiro caso, os autores atribuem a ausência de associação a uma dificuldade de mensurar e graduar a exposição solar por meio de questionários; no segundo, relaciona-se tal achado com as características da amostra estudada, em que apenas 11 dos 132 pacientes avaliados referiam exposição solar intensa e recente. Whiteman et al. ${ }^{(15)}$ também fizeram uma observação sobre o número de melanócitos e o tipo de exposição solar, se crônica ou intermitente, e verificaram um número médio de melanócitos $17 \%$ maior na região do tronco (exposição solar intermitente) do que no dorso das mãos (exposição solar crônica). Entretanto, deve-se novamente considerar a variável localização anatômica como possível fator confusional. A relação entre a densidade de melanócitos e a exposição solar é ainda uma questão bastante complexa. Estudos prospectivos com análise de biópsias de uma mesma localização em um mesmo indivíduo após períodos diferentes de exposição solar podem ser uma forma de melhor abordar o tema.

Considerando a variável gênero, em concordância com a literatura preexistente, não verificamos diferença no número de melanócitos entre homens e mulheres $(1,7,12,13)$. Em relação ao tipo reativo de pele, não observamos diferença entre os grupos na área de maior fotoexposição. Notamos uma diferença matemática entre os grupos IIII-IV e V-VI apenas na área fotoprotegida. Esse achado pode estar relacionado com a forma irregular de distribuição dos indivíduos pelas categorias e pela grande variabilidade das medidas nas diferentes regiões. Nenhum dos estudos anteriores evidenciou diferença no número de melanócitos e a cor da pele ${ }^{(1,7,8,12,13,15)}$. A tonalidade da pele está relacionada provavelmente com a produção, a distribuição e a degradação da melanina.

A idade como fator influenciador da densidade de melanócitos foi analisada inicialmente em amostras pequenas ${ }^{(5,}$ 7) e em localizações anatômicas distintas ${ }^{(12)}$, ficando ainda controverso se havia diminuição do número dessas células com o envelhecimento. Whiteman et al. ${ }^{(15)}$ e Hendi et al.(6) descreveram uma correlação inversa entre o número médio de melanócitos e a idade. A nossa série incluiu uma ampla faixa etária, de 1 a 91 anos, existindo uma tendência a uma diminuição do número de melanócitos com a idade.
Tal achado só foi estatisticamente significativo na região glútea (área fotoprotegida). É possível que a fotoexposição possa ter atuado como variável de confusão nessa avaliação, elevando o número médio de melanócitos dos pacientes com maior idade. Vale citar como exemplo o indivíduo de número seis, com 91 anos e um número médio de melanócitos de 14,9/CGA na região do antebraço (área fotoexposta) e 2,1/CGA na região glútea (área fotoprotegida).

Outra observação importante foi a diferença na distribuição dos melanócitos em um mesmo fragmento de pele. Em uma amostra de pele do antebraço, identificamos setores com quatro melanócitos/CGA, contrastando com setores contendo 20 melanócitos/CGA. De forma semelhante, porém com menor intensidade, essa irregularidade na distribuição também foi verificada nas amostras da região glútea, com valores de um a 10 melanócitos/CGA em um mesmo fragmento. Dessa forma, a proporção média de um melanócito para cada dez ceratinócitos basais, informação primeiramente fornecida pelos estudos de Cochran ${ }^{(2)}$, Rhodes et al. ${ }^{(10)}$ e Fallowfield et al. ${ }^{(8)}$, é uma medida bastante generalista para ser aplicada como parâmetro para a prática médica de rotina. Barlow et al.(1) também chamaram atenção para essa grande variação na densidade e na distribuição dos melanócitos, ressaltando que a definição de um padrão de "normalidade" para esse tópico é muito problemática.

No sentido de trazer informações úteis para a interpretação de biópsias de pele com lesões melanocíticas, Hendi et al. ${ }^{(6)} \mathrm{e}$ Barlow et al. ${ }^{(1)}$ avaliaram de forma mais detalhada a distribuição dos melanócitos pela epiderme. Hendi et al.(${ }^{(6)}$ observaram na pele com fotoexposição crônica da região da cabeça/pescoço uma média de 15 a 20 melanócitos/ CGA, com presença de confluência em $89 \%$ das amostras, a maior parte foi considerada leve (dois melanócitos lado a lado), porém chegou a encontrar até nove melanócitos dispostos de forma contínua. Barlow et al.(1), ao avaliarem fragmentos de pele da região de cabeça/pescoço, tronco, membros superiores e inferiores, relataram o encontro de confluência de três a quatro melanócitos em $16,7 \%$ da sua amostra, sendo mais frequente nas áreas de maior celularidade, caracterizando a principal alteração morfológica identificada na sua série. Em nosso trabalho, encontramos a presença de confluência de melanócitos tanto nos fragmentos de pele obtidos do antebraço (área exposta) como nos da região glútea (área coberta). Tal achado foi mais frequente na área de maior fotoexposição, presente em $66,3 \%$ dos casos dessa amostra. Deve-se notar também que, assim como descrito em estudos anteriores, a confluência foi mais evidente nos fragmentos que mostraram os 
maiores índices de densidade e celularidade. Na maior parte de nossos casos, essa confluência representou a presença de dois a três melanócitos dispostos lado a lado, não se identificando em nenhum dos fragmentos mais que quatro melanócitos dispostos de forma contínua.

Evidenciamos também em nosso estudo alterações da forma e características celulares. A atipia citológica foi identificada apenas nos fragmentos de pele obtidos do antebraço, área de maior exposição solar, e esteve presente em $40 \%$ das amostras. Fallowfield et al. ${ }^{(4)}$ apresentaram resultado similar em seu trabalho, verificaram a presença de atipia citológica em $50 \%$ dos fragmentos de pele obtidos do antebraço (área de maior fotoexposição). Relataram também o achado de atipia citológica leve em seis das 84 biópsias obtidas da região glútea (área coberta). Ressaltaram que, desses seis casos, quatro pacientes apresentavam história de melanoma e dois de nevo displásico. Dessa forma, sugeriram que a presença de melanócitos anormais na pele coberta (região glútea) poderia indicar um indivíduo com maior suscetibilidade de desenvolvimento do melanoma.

Tentamos analisar em nossos casos se havia alguma influência do envelhecimento na alteração da morfologia dessas células. Observamos a presença de atipia em indivíduos com idade entre 22 e 88 anos; e $66,6 \%$ dos indivíduos que não exibiram atipia citológica possuíam idade superior a 60 anos. Essa observação sugere que existam outros fatores individuais que alterem o meio ambiente celular e, por consequência, modifiquem a morfologia microscópica do melanócito, não obrigatoriamente relacionados com o envelhecimento. Esse achado também está de acordo com a ampla faixa etária de acometimento do melanoma, que ocorre inclusive em crianças e jovens.

Em nosso trabalho, assim como no de Hendi et al. ${ }^{(6)}$, não foram identificadas a formação de ninhos nem de disseminação pagetoide em nenhuma das amostras. Barlow et al.(1) relataram a presença de ninhos em dois dos seus 180 casos e de disseminação pagetoide em um. Weyers et al. ${ }^{(14)}$ encontraram apenas um pequeno ninho de quatro melanócitos na pele com fotodano em 100 casos, e notaram em seis destes a presença de melanócitos acima da junção dermoepidérmica. Dessa forma, acreditamos que a presença de ninhos e de disseminação pagetoide até os terços superiores do epitélio são importantes critérios para a definição de proliferação neoplásica de melanócitos. Já a distribuição irregular, a confluência e a atipia citológica não devem ser utilizadas de forma isolada para o diagnóstico dessas lesões.

Por se tratarem de fragmentos de pele obtidos de cadáveres do SVO, não foi possível coletar informações precisas sobre o histórico de câncer de pele em nossos pacientes. Diversos autores avaliaram a influência do antecedente de neoplasias cutâneas, principalmente melanocíticas, na densidade e nas características morfológicas dos melanócitos. Entretanto, trata-se de assunto ainda controverso na literatura. Fallowfield et al. ${ }^{(3)}$, Whiteman et al.(15) e Hendi et al. ${ }^{(6)}$ não verificaram alteração na densidade, distribuição e morfologia dos melanócitos da pele adjacente a neoplasias melanocíticas estatisticamente diferente daquela encontrada na pele com fotodano. Apenas Barlow et al..$^{(1)}$ detectaram um número significativo maior de melanócitos na pele adjacente a tumores melanocíticos. Essa alteração, primeiramente descrita por Wong ${ }^{(16)}$ em 1970, ficou conhecida como "efeito de campo" e foi usada como justificativa para a ampliação de margens de ressecção no tratamento dessas lesões. A maior parte dos autores atualmente atribui esse achado de "efeito de campo" na pele adjacente a tumores melanocíticos apenas ao fotodano, pois também está presente na pele adjacente a tumores não melanocíticos e, inclusive, na pele sem lesão macroscópica, como observado em nosso trabalho ${ }^{(3,6,14)}$.

O estudo complementar por imuno-histoquímica para a contagem de melanócitos não parece fornecer valores diferentes da análise realizada pela coloração de rotina ${ }^{(8,15)}$. Apenas Hendi et al.(6) recomendaram o uso dessa metodologia para a avaliação intraoperatória de margens de ressecção durante a cirurgia de Mohs, pela dificuldade na interpretação da morfologia dos melanócitos quando com artefatos decorrentes do congelamento.

\section{Conclusão}

Há grande variabilidade da densidade, distribuição e morfologia dos melanócitos na pele humana. Na pele fotoexposta, verificaram-se número maior de melanócitos, confluência mais frequente e atipia citológica. Não foram verificadas, em nenhuma das amostras, a formação de ninhos e, tampouco, a disseminação pagetoide.

\section{Comentários}

Parâmetros de normalidade são muito difíceis de definir, o que torna, muitas vezes, problemática a interpretação de biópsias de pele, principalmente para o diagnóstico de 
lesões iniciais e para a avaliação precisa das margens de ressecção. A irregularidade da distribuição, a confluência de melanócitos e a atipia citológica devem ser sempre avaliadas conjuntamente com outros fatores para a determinação do diagnóstico de melanoma, entre eles, principalmente, a formação de ninhos e a presença de disseminação pagetoide.

\section{Referências}

1. BARLOW, J. O.; MAIZE, j.; LANG, P. G.The density and distribution of melanocytes adjacent to melanoma and nonmelanoma skin cancers. Dermatol Surg, v. 33, n. 2, p. 199-207, Feb. 2007.

2. COCHRAN, A. J. The incidence of melanocytes in normal skin. J Invest Dermatol, v. 55, p. 65-70, 1970.

3. FALLOWFIELD, M. E.; COOK, M. G. Epidermal melanocytes adjacent to melanoma and the field change effect. Histopathology, v. 17, p. 397-400, 1990.

4. FALLOWFIELD, M. E.; CURLEY, R. K.; COOK, M. G. Melanocytic lesions and melanocyte populations in human epidermis. Br J Dermatol, v. 124, p. 130-4, 1991.

5. GILCHREST, B. S.; BLOG, F. B.; SZABO, G. Effects of aging and chronic sun exposure on melanocytes in human skin. J Invest Dermatol, v. 73, p. 141-3, 1979.

6. HENDI, A.; BROLAND, D. G.; ZITELLI, J. A. Melanocytes in long-standing sun-exposed skin: quantitative analysis using the MART-1 immunostain. Arch Dermatol, v. 142, n. 7, p. 871-6, Jul. 2006.

7. MITCHELL, R. E. The effect of prolonged solar radiation on melanocytes of the human epidermis. J Invest Dermatol, v. 41, p. 199-212, 1963.

8. LeBOIT, Philip E. et al. World Health Organization Classification of Tumours. Pathology and genetics: skin tumors. Lyon: IARC Press, 2006.
9. QUEVEDO, W. C. et al. Melanocyte populations in UVirradiated human skin. J Invest Dermatol, v. 45, p. 295-8, 1965.

10. RHODES, A. R. et al. Risk factors for cutaneous melanoma. A practical method of recognizing predisposed individuals. JAMA, v. 258, n. 21,p. 3146-54, Dec 41987.

11. SALVIO, A. G.; MARQUES, M. E. A. Imuno-histoquímica para identificação de células neoplásicas no infiltrado ativo de melanomas finos. J Bras Patol Med Lab, v. 42, n. 2, p. 143-8, Abr. 2006.

12. STARICCO, R. J.; PINKUS, H. Quantitative and qualitative data on the pigment cells of adult human epidermis. $J$ Invest Dermatol, v. 28, p. 33-44, 1957.

13. SZABO, G. The number of melanocytes in human epidermis. Br Med J, v. 1, p. 1016-7, 1954.

14. WEYERS, W. et al. Melanoma in situ versus melanocytic hyperplasia in sun-damaged skin: assessment of the significance of histopathologic criteria for differential diagnosis. Am J Dermatopathol, v. 18, p. 560-6, 1996.

15. WHITEMAN, D. C.; PARSONS, P. G.; GREEN, A. C. Determinants of melanocyte density in adult human skin. Arch Dermatol Res, v. 291, n. 9, p. 511-6, Sep. 1999.

16. WONG, C. K. A study of melanocytes in the normal skin surrounding malignant melanoma. Dermatologica, v. 141, p. 215-25, 1970. 